\title{
The invisible plan: how English teachers develop their expertise and the special place of adapting the skills of lesson planning.
}

Keywords: English teaching, teacher cognition, Teacher planning, expertise development, tacit dimension.

\begin{abstract}
:
This paper analyses how English teachers learn to become expert designers of learning and why sharing that expertise is increasingly vital. Its conceptual framework is the widely recognised, empirically tested, five-stage developmental Dreyfus model of skill acquisition, exemplifying the development of teacher expertise - see Goodwyn (2017a), constituted by the 'milestone' $[\mathrm{m}]$ and 'transitory' [t] phases connecting with the five (5) stages of: Novice [m], Advanced Beginner [t], Competent [m], Proficient [t] and Expert [m]. Teacher planning is analysed as one key tacit or non-tangible component of developing expertise. Focusing specifically on English teachers as key participants in this pioneer teacher cognition study, the defining characteristics of milestone stages of expertise development are explored with specific attention to the remarkably under-researched area of planning. We introduce three new categories, defining modes of planning, (i) visible practical planning, (ii) external reflective planning and (iii) internal reflective planning demonstrating their role in teacher development through the Dreyfus five (5) stages. Implications for practice include an explicit understanding of how teachers' planning moves through the three phases. Further research is needed to explore how English teachers in particular can share planning expertise between the three phases to improve teachers' skills and student learning.
\end{abstract}

\section{Introduction:}

A considerable body of research in education concludes that teaching is remarkably complex (Sinnema et al., 2017; Loughran, 2013; Lampert et al., 2013; Loughran, 2010; Hewitt, 2008; Hall and Smith, 2006). This article explores our current understanding of the nature of its inherent complexities in relation to teacher development over time and especially in relation to English teachers and their modes of planning. The complexities of teaching are also infused with the globally acknowledged intricacies of English as a subject (Matthewman, 2014; Exley and Chan, 2014; Goodwyn, 2011; Colarusso, 2010; Gibbons, 2009; Sperling and DiPardo, 2008). 
Currently there are many commendable 'Handbook' style guides to planning for English teachers, especially novices. However, apart from Goodwyn's research (2011) based on book length examination of the development of novice English teachers and the work of their specialist mentors (Goodwyn, 1997), there is little actual research about how English teachers describe their planning processes. As a result, much of the research literature discussed here, and the underpinning Dreyfus schema, is necessarily generic and our argument and findings should be of interest beyond English teaching. However, we are careful to underline that our evidence here comes exclusively from English teachers and is analysed through a subject specialist lens and a recognition of the rapid policy changes that impact the subject, almost certainly more than any other (Gibbons, 2017). As this article seeks to establish a new conceptual approach to planning and introduce innovative terminology, quotations from English teachers are necessarily selective and chiefly illustrative of key ideas.

Much research has demonstrated the many tacit components of complexity (Loughran, 2013; McGill, 2007), 'hidden' teacher concepts of Bildung and Didaktik (Hopmann, 2007), and Ryan (2011). Teacher planning may be characterised as 'very visible' for novices (herein taken to be student teachers and Newly Qualified Teachers - NQTs) but expert teachers' planning becomes 'invisible' once fully internalised. By planning we adopt a simple definition that is 'the design of learning for groups of students', planning might be long or short term, here we focus principally on the lesson as the unit and clarify that 'design', whilst quite static and fixed for novices, becomes dynamic and fluid for experts. 'Planning' for experts becomes more a mode of experimental improvisation that draws on deeply internalised cases of previously successful learning designs. The research evidence informing this article comes from a pioneering study of English teachers focusing on their thinking (Teacher Cognition), their levels of expertise and uses of learning designs (Enow, 2016). This teacher cognition study used a qualitative multimethod design incorporating seven (7) data 
collection methods: think aloud, interview, reflective log, questionnaire, simulated recall, expert commentary, and critical incident report (Enow and Goodwyn, 2017; Enow 2016), and worked with a sample of fifteen English teachers within the milestone stages of Novice, Competent, and Expert. Data collection was recursive, reflective and evaluative of lesson design thinking. Think aloud, a verbal rendition of thinking, revealed the typically internal pre-lesson planning process. The interview showcased peculiarities of change processes involved in lesson design thinking. For post-lesson activities engaged in by the English teachers, audio-recorded reflective log and critical incident report methods were used. Stimulated recall provided in-depth explanations and rationale for targeted components of the lesson design. Expert commentary generated the opportunity to evaluate sample lesson designs. With the questionnaire, the interest was in career information, particularly expert status. The focus on cognition necessitated data which captured the predominantly nonsequenced mode of thinking.

There is an intricate constitution to all teachers' thinking during planning, forming the foundation of the interactive teaching phase and enabling the post-active reflective phase; see Mena Marcos et al. (2008), and planning necessitates the interplay of several cognitive processes. Some key examples of cognitive processes in teaching include, decision making (Eley, 2006), teacher professional judgement (Gholami, 2011), problem solving (Chua et al., 2016) and pedagogical reasoning (Vesterinen et al., 2010), etc. One 'launch pad' (Marcos, 2008) of cognitive processing is captured in the study by Plaut (2006) on the valuable role necessary confusion plays in learning. For example, a participant in the study Katie reflects:

“so...I'm trying to think, I don't know if I want a whole class feedback or I want sort of peer assessment. I might ask them, mm, they're already showing me that they're understanding or not, I'm not a big fan of 'thumbs up - thumbs down', although I do it with their eyes closed, I still feel like some of them just won't put their hands down 
if they, if they're not sure. What I might do is, if they punctuate the sentence, mm

(PAUSE) Yeh ok, so what I might do is; put another paragraph on the board quickly".

This extract helps reveal the tentative and improvisational nature of fluid teaching for one experienced English teacher. This study used a holistic format (see Tirri \& Ubani, 2013) examining all aspects of teacher thinking especially through the 'think aloud' approach. Data collection using think aloud enabled, the participants who were all teachers of English to plan a lesson while verbalising, hence externalising, thought processes involved in lesson design. Hollins (2011), in discussions about novice teachers, identifies a priority for educational research to emphasise elements of teaching which are not tangible, such as planning. Hollins (2011) argues that such research assists in 'surfacing' cognitive processes, subsequently seeking to understand them as part of teachers' long term development. From the perspective of Hall and Smith (2006), such a holistic outlook combines three key components of teaching: planning, instruction and reflection, revealing their overall impact on cognitive processes. Although not limited to cognitive processes, Waring and Evans (2015) encapsulate what 'holistic' means, specifying a complex mesh of both visible, and arguably observable, and embedded influences affecting both teacher and student in the context of social, economic and policy factors (see also Badjanova and Iliško, 2015) although this conceptualisation has been challenged in CEM (2014). English teaching is a particularly striking example of a contested subject domain (Goodwyn, 2011; Gibbons, 2017) subject to constant policy imperatives and therefore requiring new learning designs even for the most experienced teachers. The contested nature of English and its prominence in the school curriculum demands deeper insights into lesson design by English teachers at various levels of expertise development in order to meet its evolving demands. Returning to Hall and Smith (2006), they conceptualise teaching within a pre-active stage, typically the learning design/lesson planning stage, inclusive subsequently of interactive and post-active stages. 
This vital point provides a profound contrast to the current reductive behaviourist policy emphasis on performance management through observing solely the interactive, that is 'live' teaching stage (Swinson and Harrop, 2012; Woollard, 2010). Research by Moran (2008) demonstrates that most observation of teachers is reductive and conducted solely for the purpose of accountability (West et al., 2011) rather than enhancing teacher quality (Slater et al., 2012; Ingvarson and Rowe, 2008). Significant recent summaries of research, for instance Coe et al. (2014), contain a key message similar to that by Maclellan (2012) entreating more research on teaching should be derived from studies of cognition and metacognition with a view to deepening our understanding of the complexity of teaching. Our paper adheres to this call in our summary of the research evidence on lesson design from the teacher cognition study (see Enow, 2016).

Informed by this extensive research evidence, this paper engages specifically with the complexities of planning in English teaching. All this accumulated research underpins our focus (O’Neill et al., 2013) on how these non-observable, non-tangible dimensions in turn showcase levels of expertise development (Goodwyn, 2011). There remains the probability that despite the generally agreed knowledge of its complexities, understanding teacher thinking remains at the elementary stages. We examine these complexities in relation to the development of teacher expertise amongst English teachers and their planning processes, describing a reflective continuum consisting of milestone stages and transitory stages, adopting the Dreyfus model which illuminates and explains this professional journey.

\section{The Dreyfus model and teacher expertise}

There are a number of models of expertise for example the Kinchin and Cabot model, (Kinchin and Cabot, 2010), the Dall'Alba and Sandberg model (Dall'Alba and Sandberg, 2006) and the Model of Domain Learning - MDL (Alexander, 2003). We present the Dreyfus 
model and argue that its graduated five stages present a realistic frame to examine the teacher expertise development continuum with the understanding that teaching is a life-long profession. The developmental Dreyfus model of skill acquisition (Goodwyn 2011; Dreyfus, 2004) constitutes the stages: Novice, Advanced Beginner, Competent, Proficient, and Expert and has been utilised by influential researchers in education (Goodwyn, 2011; Hallam, 2010, Berliner, 2004). Goodwyn, in particular $(2011 ; 2016)$ has used it in examining the concept of the expert teacher of English, but with relatively little attention to pre-active learning design. The Dreyfus model has been employed effectively for over 30 years in the study of skill development across a range of professions - Social Work, Nursing and Dental Medicine (Ryan, Fook \& Hawkins, 1995; Benner, 2004; Lyon, 2015;) and is considered a robust and reliable model, although the Dreyfus model is not without its critics, for instance Dall'Alba and Sandberg (2006) identifying the fact that this is a theoretical model. To counter this criticism, it is important to specify that the first empirical application of the Dreyfus model in teaching is in research with English teachers (Enow, 2016).

The application of the Dreyfus model to teaching enables an enhanced understanding of what teaching involves, which can help drive the improvement of every English teacher, with the focus on the holistic quality of teaching (Ingvarson, 2010), and not the reductive view so often featured in models of mechanistic 'performance management'. Inevitably all English teachers begin at a novice stage and this term 'novice' is important to be seen not as a problem but as an entitlement, as Goodwyn demonstrates in Developing English Teachers (Goodwyn, 1997), a book focusing on novices and highlighting their developmental needs. What the Dreyfus model provides is a clear means to set appropriate expectations of a novice English teacher, and a means to enable progression to the Advanced Beginner [AB], typically consolidating at the Competent stage. Many teachers spend a long period as competent for very good professional reasons as explained in Goodwyn (2011), however the model 
provides a clear pathway for 'more' development beyond this form of 'plateau' (Ward et al., 2013) of stability. Many countries have recognised the need to incentivise and reward teachers to push above the plateau with models such as The Advanced Skills Teacher (AST) in England and Wales, English teachers were well represented amongst ASTs (Goodwyn, 2017a), and the current Specialist Leader in Education (SLE) model.

Using a 'stages' model like Dreyfus does not exclude the valuable metaphor of the graduated incline towards expertise as a steady, effortful process (Betsch and Glockner, 2010) constituting actively seeking and infinitely refining permutations in planning geared towards spontaneity and automaticity (Berliner, 2004). The Dreyfus model is not a strait jacket and is conceptualised as differentiated because, for example, professionals are using many skills at once, including developing new ones, so they can be novices in one area whilst quite expert in many others.

Nevertheless, the five stages provide a broad means of identifying reasonable expectations of teacher planning development within each of the stages. The expectation overall is of a gradual and systematic incline towards planning expertise which is efficient both for professional learning and interactive delivery evaluation. Much research also demonstrates that expertise is 'situated', that is context-specific (Lajoie, 2003; Peercy et al., 2015), with change in context compromising the pace of expertise development. Secondary English teachers, for example, would not transfer easily to teaching literacy in a primary setting or to teaching English as a second language and they are aware of these contextual limitations. For example, there was very interesting evidence of how much English teachers came to appreciate the expertise of primary teachers, especially their planning, during the National Literacy Strategy between 1998 and 2007 (Goodwyn, 2002). In essence, based on the examples provided, planning should be approached with consideration taken of the stage of expertise development, and particularly for English teachers noting areas of specialism and 
Key stage delivery. This illuminates individual fluidity in terms of planning, but also suggests essential collaborative possibilities within contexts such as Key stages, potentially enabling group, as well as individual, expertise development (see Peercy et al., 2015). Further research could investigate how collective expertise in planning is developed.

\section{English teachers and planning.}

Enow (2016) focuses on planning as one, under researched, aspect of teaching that helps reveal the expertise continuum based on the Dreyfus model. The innovative perspective of using the Dreyfus model in researching English teachers' planning reveals important insights into teacher cognition. This research (Enow, 2016) concentrated on only secondary English teachers, including novices, all of whom had teaching opportunities mostly across the English curriculum and secondary year groups. Selection criteria for participants retained exclusivity of teachers of English in secondary schools in the UK. Participants were targeted in the Novice (new entrant into profession -Induction year), Competence category (peer validation with leadership role inclusive of minimum of six years of experience), and Expert (by Local Authority / Academy recommendation within the former AST -Advanced Skills Teacher accreditation and/or the present SLE - Specialist Leader in Education designation). Sampling was undertaken bearing in mind that years of experience is not a determinant of level of expertise (Tsui, 2009; Ericsson, 2005), rather the developmental phase established by defining features of the Dreyfus model. Data collection for the study entailed use of the following: think aloud, interview, reflective log, questionnaire, simulated recall, expert commentary, critical incident report (Enow \& Goodwyn, 2017). A qualitative multimethod design was used for the study. The focus here is on explicating the journey towards teacher expertise, exploring some characteristics of each stage, and how each stage is exemplified in the thinking which happens during English teachers' planning, this is illustrated with selected quotations from the data. 


\section{The Novice Stage:}

The Novice level, (Mutton et al., 2011), involves experimenting with theoretical knowledge, in simple terms 'trying out other people's ideas', including their lesson plans. From the perspective of knowledge, Gitomer and Zisk (2015) demonstrate that the novice continues to consolidate content knowledge while experimenting with the new dimension of subject pedagogical content knowledge (Shulman, 2013). However, this process tends to be rather mechanistic and inflexible so a plan is particularly vital and deviation from the plan is extraordinarily threatening, so the mechanics of teaching overshadow the holistic picture of the contributions of the learners. As Dreyfus (2004) specifies, in this stage the novice desires the comfort of 'following the rules', lacking any deep experience. 'Rules' tend be learned or internalised with or without a context, in a detached manner, not recognising actual students' needs. Dreyfus (2004) outlines that generally rules can be simple, but Berliner (2004) demonstrates how the complex nature of teaching defeats rule-based knowledge. For example, being told by experienced teachers 'what works', can be a foundation, but it is not guaranteed to work for the novice, however thoughtful their planning. Hudson (2013) establishes how pertinent the role of mentoring is with such planning and its place in view of support for teaching. Although neither 'mere' experience, nor years of teaching are a measure for expertise (Tsui, 2009; Ericsson, 2005), it is likely this novice experimenting phase should span some time (see Berliner, 2004). It is a sign of true expertise, post competence, that expert experimentation with fluid learning design is a constant. For a generic and more detailed exploration of lesson planning with new entrants to the profession, specifically learning construction at the pre-active stage, see Mutton et al. (2011) and Hudson (2013). Applying the categories operating in the English system, the Newly Qualified Teacher (NQT) - (Gorard, 2017; Hagger et al., 2011;) is in the Novice category. Research on teacher education has captured the difficulties of this stage, for example, in Finland (Blomberg and 
Knight, 2015), similarly a US study (Strom, 2015). While acknowledging the challenge for novices (Kumi-Yeboah and James, 2012), the study celebrates the success of an award winning novice teacher. Although the generic description of the novice of being within three years of teaching is different to the study by Enow (2016) which uses the system in England of post QTS or Induction Year as a starting point, there is a convergence of evidence of the challenging nature of this developmental phase.

One element of the Teacher Cognition study by Enow (2016), used think aloud protocols, that is when participants speak out their thought processes, shown in the instance below, when considering how to teach an English lesson with a lesson focus on complex sentences. The experimenting potential of the novice is inferred from this excerpt by Nathan, one of the participants in the study by Enow (2016):

“That's not crystal clear but that'd be my, the gist of where I'd go. I haven't written it all down, I can write it down, em, Teen Fiction and then, er, plot points, (WRITING) ...theory, clarity and effect...and complex ones...for sophistication and detail... yeah, I think that's what I'd do. I've never actually taught that, complex sentence lesson before, but so, em, I'd actually be more comfortable, I think if I worked with Key Stage 5, I'd be more comfortable doing it, in a way I find it easier, I think on that technical basics, that's something I learned by osmosis almost, complex sentences, so it, it's, it, in a way, I find it easy to teach Key Stage 5 that register, than go right back to what, I do, I think I need a little bit more reading to it to have that meta-literacy down, write complex sentences with sophistication and detail. Yeah.”

From the excerpt of the planning thinking this would be the first time Nathan teaches this lesson; experimenting with a new lesson focus and being a novice level teacher, Nathan's 
default position to enhance theoretical knowledge is guidance texts on the lesson focus. What is striking is Nathan's sense of apparent security in teaching a complex sentences lesson at Key Stage 5, highlighting the fluidity of English as a subject; the position that topics and resources are encountered across Key Stages requiring graduated levels regarding pitching the lesson when planning. Based on Nathan's planning thinking, it should be emphasised particularly to novice English teachers that a plan is not the same as a script. It is well known how much time beginning teachers (Goodwyn, 1997) invest in highly elaborate plans, even literally scripting their words; this should be valued as a necessary stage of developing expertise. Novices are required, but also need, to make their plans highly visible and accessible to mentors (e.g. in Hudson, 2013) and other teachers and often tutors so we entitle this as external reflective planning, arguing that planning becomes an increasingly internalised and tacit dimension as teachers move to an expert stage. Distinguishing a beginner English teacher from post beginners is the expectation that all content areas would have been encountered in interactive teaching at least once.

\section{The Advanced Beginner Stage:}

Dreyfus' Advanced Beginner [AB], although still driven by theoretical knowledge, begins to amass practical examples of knowledge application, becomes more aware of learners' needs, demonstrably in their developing plans. Novice-like experimenting still persists, drawing on a small bank of examples of practice, which facilitates access to maxims (not rules) now flexibly applied to situations. Knowledge-based researchers, notably Shulman (2013), describe this as consolidating content knowledge with increasing impact on subject pedagogical content knowledge, so ABs develop more open planning and flexible teaching, producing successful and interactive English lessons. The AB appreciates the 'bigger picture' but this might not influence practice yet, since as Berliner (2004) describes, there is still limited activation of the required level of agency. There has been much research on 
novices but the $\mathrm{AB}$ phase of expertise development has had less attention. It is worth reiterating the teacher cognition study from which the research evidence for this paper has been drawn focused on the milestone stages of Novice, Competence, and Expert, therefore presenting descriptions and insights into the Advanced Beginner and Proficient stages. The Dreyfus model constitutes milestone and transitory stages (Enow 2016); and $A B$ is a transitory stage, a bridge between the Novice stage and the generally recognised Competence stage, typically achieved after a few years.

$\mathrm{AB}$ research may currently be minimal because it is a transition stage and hard to evidence, but further research would illuminate the shift on to competence, especially in an area like planning, in this case planning by English teachers. The challenge of capturing the advanced beginner stage remains across research on expertise development compromising an even precarious situation of the breadth and depth of content knowledge expected of a new teacher of English at times covering English Language, English Literature, Media and Drama, in themselves distinct subject areas. Without stating that this is impossible, especially as proficient and expert level professionals showcase this in their daily interactive teaching, it illuminates the challenge for new entrants into the teaching profession choosing to teach English and the way forward for them in handling pedagogical content knowledge. Planning by the $\mathrm{AB}$ retains some of the characteristics of the novice although it is evolving towards the competence stage.

\section{The Competence stage:}

Teacher competence is characterised by a mental store of lesson plans and 'real' examples (Enow, 2016; Goodwyn, 2011). Typically, an English teacher at this stage, say 5-10 years, has taught across the entire curriculum area, and has had multiple opportunities to engage with interactive complexities. A very significant step up from the other two stages is a high 
degree of confidence, an emotional component, for Dreyfus the 'emotional investment' (2004) - which is non-cognitive, this stems from knowledge by the competent level teacher of consistently effective lessons and that planning, still 'visible' planning, is only a guide to the lesson interaction. The interview part of the data collection which focuses on changes to a lesson plan prior to its delivery by Courtney; a competent level teacher, provides an example:

"What I usually, or the reason that I like a lesson plan like this, apart from the fact that it is really structured, is that a lot of it is very based on me and my board pen so it's very flexible when you are actually in the room. So if you get in the room, the only thing that you need to have is the model paragraph typed up. And it's only 5 sentences long, so I mean, I am confident enough with the sentences that I can type something new on the fly"

Whereas the novice tends to be dependent on the plan, usually a very teacher-focused, written lesson plan, the competent level teacher exhibits a student-centred approach (Tirri \& Ubani, 2013) and feels confident to generate examples, seemingly without much prior planning. It could be argued a more structured form of planning might produce enhanced quality of the intended example. Alternatively, the competent level teacher could be drawing from the bank of used and already internalised examples. Shulman's research (2013) demonstrates how confidently such teachers combine content knowledge, subject pedagogical content knowledge with curricular knowledge.

Competent level teachers [certainly in England] tend to be the most busy teachers (Goodwyn, 2011), usually also occupying a middle leadership position in school, which is a quite different expertise from teaching. There is strong probability that the 'busy-ness' of new leadership detracts from the opportunity to forge beyond competence and head towards 
proficiency, and ultimately expertise. In a way, after achieving competence in teaching, the potentially expert teacher typically acquires instead an essentially novice level role in leadership. Research is yet to capture the impact on expertise development beyond competence of the nature of this career development opportunity. Many Heads of English are clearly expert teachers as well as managers, (Goodwyn, 2017b; Goodwyn, 2011) but for many teachers it may be a case of 'arrested development', using their 'tried and tested' plans and avoiding experimentation, to cope with the lack of mental space. 'Arrested development' could be extended to teachers too without leadership responsibility as has already been noted with 'plateauing'. To emphasise the nature of this period of teacher development we suggest the phrase visible practical planning. We are not suggesting that competent teachers are not reflective but we do have evidence that much of their mental space is occupied by out of class concerns such as leadership. Therefore, their pre-active reflection for many lessons is minimal and is often a quick rehearsal of what has reliably worked well, and it safely works well again. It is significant that the original designation of the AST in 1997, insisted on no management responsibility, (Fuller, in Goodwyn, 2016). To exemplify, Eric, a competent level teacher responded to a question on what would influence choice of lesson activities:

"I think experience of doing things. You, you become aware of, er, things that work. Now, not everything works with every group. So you tend to start the year with things that you know are gonna work. You refine your, I might think I'd refine my, er, choice of what we do as I get to know the group better, as I understand who's in there, so part of part of it is differentiation, partly it's, it's the relationship that I have with different students within the group, you know, knowing what's gonna be useful to them, what's gonna be, what's gonna help to push them".

Although Eric's example highlights the use of tried and tested methods, it also reveals the emotional content, that of relationships. At the level of competence, the teacher is heavily 
involved emotionally in their work. This is not to say Novice and Advanced beginners do not have emotional engagement, but the emotional involvement of the competent teacher drives their expertise development. The danger is that of career plateauing (Farrell, 2014); in the case of teachers the suggested term of pedagogic plateauing. To be more explicit, while the novice and advanced beginner teachers can still see what they need to learn, the competent level teacher risks feeling comfortable with what works and has worked for many years. This could in turn generate rigidity; an antithesis to pedagogical growth, thwarting the prospect to progress to proficiency and expertise.

\section{The Proficient Stage:}

Maclellan (2012), demonstrates that at the proficient stage, all teaching aspects are handled flexibly in multiple permutations, covering all items within the subject area, adopting endless permutations, varied outcomes are derived, mentally 'stored', refined and reused, the finer details, nuances and changes in outcomes now guide amendments. In essence, the proficient level teacher $[\mathrm{PT}]$ refines the totality of input acquired during competence and works constantly, often experimenting to develop excellent outcomes. Whereas the competent, but non-expert, professional treads steadily in risk averse territory, Moran (2008), shows that engaging with expert level performance is intrinsically pro risk-taking, not indulgently, but calculating and often research-informed; Jóhannesson (2006), the PT draws on a huge store of tried and tested plans, providing a sound platform for considered experiment. The PT actively researches how pedagogical content knowledge works in various circumstances, identifying varying degrees of impact on quality of learning, continually open to input from learners to guide interactive refinement. To the Novice English teacher, a PT seems not to engage with formal and explicit planning, but significantly they are actually using internalised plans, we characterise PT [and expert] planning as 'internal reflective planning', not least because much of it occurs during teaching. 
The following examples of the internal reflective planning of the expert English teachers participating in the study, reveal how they are striving for quality beyond competence:

"I'd prepared lessons before and it, it was ok, they were, they went through the motions because they were ok kids and we had a good relationship. But we weren't really, em, I didn't feel [our emphasis] that we were really breaking through in any way, I didn't, didn't sense that they were understanding. What I sensed [our emphasis] was they were doing it because it was me and instead they were just completing the work' (Brian).

Similar to the competent level teacher Brian demonstrates emotional involvement. It is almost paradoxical that based on Brian's relationship with his students he worries that the students are compliant rather than intrinsically engaged and enthused. Now, it is possible that a novice or maybe an advanced beginner, could observe this and 'read' it potentially in a different way. A professional at the proficient stage uses emotional filters to ensure that learning happens for the right reasons and the long term benefit of the learners; the relationship the proficient teacher has with the students demands this, and nothing else. Brian's need to establish the underlying motivation for learning is captured in the excerpt below:

'I also felt I wanted to move away from the PEE paragraph structure; PEE standing for Point, evidence, explanation. Em, it is a structure used regularly by most teachers nowadays but I believe it leads to very predictable essays; all sounding the same, very mundane. And if you've got bright kids, I do believe it, that, it, em, stunts any attempts of flair to break out of that structure' (Alice; an expert teacher).

This excerpt from Alice, similar to Brian's, emphasises the need to look beyond the students' output to focus on what has really been learned. While planning her lesson using the think 
aloud protocol, Alice filters her planning looking at how students will structure their output ensuring her support to attain a level of performance which enhances their aptitude. Based on Alice's analysis, PEE paragraphs will enable the students to generate relevant output, however Alice is willing to take a risk with the learners by eliminating the scaffold or the structure. This is not reckless risk-taking, it is decision making borne of outstanding knowledge of the learners derived from the teacher / student relationship. These highly accomplished English teachers have attained the appropriate level of attributive features (see Hattie, 2003) to facilitate learning, their plan is to create the space to ensure that deep learning is happening (Hattie, 2012).

Memory, one of the seven cognitive processes identified by Enow (2016), plays a vital role in the post competent stages. Shulman (2013), demonstrates that these 'almost expert' teachers have outstanding content knowledge maintained by interest in contemporary research, refined subject pedagogical content knowledge and a holistic picture of curricular knowledge. This latter knowledge is inclusive of policy prescriptions but not reduced or constrained by it. From the empirical study (Enow, 2016), it has been established that the proficient stage exhibits features of a transitory phase with similarities to the nature of the $\mathrm{AB}$ stage but clearly post competent.

\section{The Expert stage:}

Teaching as a profession has finally arrived at a significant moment, when there is abundant acknowledgement by authoritative bodies across the globe [and some teachers themselves] that they are experts (Goodwyn, 2017a). The empirical from this research, a qualitative study of secondary English teachers, demonstrates that expert teachers have all of the characteristics of the proficient teacher but also exhibit automaticity that allows for constant spontaneity and fluid performance (Berliner, 2004). If the PT reveals an effortful process, the 
expert makes teaching look effortless so that the observing novice notices only seamless student learning (Goodwyn, 1997), with the extensive range of the effortful procedures becoming 'invisible' in the tacit dimension. This 'illusion' extends to planning with the expert unable to show detailed plans for the novice to follow. However, we argue that planning has become internal reflective planning, tacit and hard to articulate, seemingly 'invisible'. The speed of information retrieval, overall reading of the interactive phase and elimination of problems almost eradicating the need for problem solving (John, 2006). With an expert English teacher, there is a well-managed flow maintained throughout every interactive phase of teaching, but this continuum demands ongoing processing, these English teachers always have the planned ideal lesson 'in their heads' but they constantly adapt and adjust in real time to make this particular, 'real' lesson, still ideal.

We would suggest here that the predominant model of English teachers, 'Personal Growth' (Goodwyn, 2017b), is especially sensitive to constant interaction with students and their contributions to the learning of the class, meaning that they are especially expert at internal reflective planning which is a process often happening during interaction. This sensitivity is indispensable particularly in teaching because each teaching opportunity is dynamic and remains unique (Gibson and Ross, 2016). Further research would be needed to investigate how a subject model like Personal Growth may be an important factor in developing the planning of English teachers who work with a particularly wide range of subject content. English teachers, unlike the chess players captured in expertise studies where rules and moves are stable, therefore have one of the greatest challenges in that their profession is one with constant, 'ever-changing', elements, not just unique learners. In English incessantly there are new curricular and assessment changes and also rapid policy shifts. It can be argued that the expert English teacher, because the subject is so much subjected to constant 'reform', will have to continue to work incredibly hard, and in an effortful manner, to sustain 
performance at the peak (Ericsson and Pool, 2016) of the Dreyfus model. Enow (2016: 212) illuminates thus:

"However, the strong fluid pedagogical content knowledge position of the expert incubates the lesson components effortlessly, implying planning for the expert begins with a solid foundation of learner prior knowledge, excellent knowledge of datarelated insight of the groups, deep psychological and emotional insight of each individual in the group, as well as up-to-date knowledge of whole school and national expectations. The expert, therefore, begins planning at an appropriate point in the past, factoring immediacy and empowering learners for independence, and further exploration in the future".

\section{Conclusions}

It has been widely acknowledged nationally (Goodwyn, 2011), and internationally (Goodwyn, 2017a) that advanced systems of education need to find ways to recruit and retain the best teachers in the classroom and to develop career structures, such as The AST, that actively promote expert teaching and the concept of teachers as leaders of learning. For the best English teachers, currently there is no such national system although some schools have, for example, 'Leading Practitioner' posts which have some elements similar to AST roles. The Dreyfus model provides a useful and robust framework for conceptualising the journey towards becoming an expert English teacher; a model presented, reviewed, elaborated on and theorised about for over two decades, with a contemporary empirical study (Enow, 2016) demonstrating its applicability to planning. The Dreyfus model empowers teachers to take responsibility for their own professional learning, through the self-evaluation generated in the post-active stage of teaching and subsequent situating within the expertise continuum, 
providing a shared language to help understand teacher quality with primarily a developmental outlook (Ericsson and Pool, 2016) suitable to a specific stage of teacher expertise development. For all English teachers, this approach aids the recognition of teachers as experts, and helps substantiate claims for public and professional recognition.

We began by stating that teaching is complex and that this complexity is certainly further complicated by the tacit component, most of all in teacher planning. McGill (2007), emphasises that to truly understand teaching we must consider the non-observable dimensions, proposing the journey towards expertise involves an increasingly important tacit dimension. Our focus has been learning design/planning as the activity to explore the nature (or composition) of expertise development of English teachers. A model for describing planning which reflects stages in expertise development is introduced: 1) external reflective planning, 2) visible practical planning, and 3) internal reflective planning; corresponding to the milestone stages [m] of Novice, Competent and Expert.

We are not arguing for making teaching seem less complex, however, in order to study it, we theorise that each developmental phase presents its complexities with usefully representative characteristics that are broadly and generally revealing of that phase. Teaching is complex because few constituents are fixed and interacting with learners remains a dynamic process which changes during each session (Loughran, 2013) and we believe this is especially true of the English classroom (Goodwyn, 2011) and each session is understood in this paper from the holistic fluidity of pre-active, interactive and post-active considerations, (Enow, 2016; Mena Marcos et al., 2008; Plaut, 2006; McCutcheon and Milner, 2002) as well as the myriad ways in which the 'holistic' in pedagogical terms is presented for instance by Waring and Evans (2015). Jóhannesson (2006: 32) argues: 
“...if expertise is located in people as educational capital, as in the view of Bourdieu, then teachers need to acknowledge their own expertise by focusing on how they use it not only as an expert group but also individually".

Some of our findings on planning and expertise may well be applicable beyond the English subject area, some elements of teaching are clearly generic. However, advanced teacher thinking tends to be specifically subject-related (Goodwyn 2017a). Perhaps, for example, the composition of thoughts and the embedded processes concerning planning could be transferable? We consider that for the purposes of this paper, not least because all the data for this teacher cognition study was collected only from English teachers, so our insights should be taken into consideration primarily for the professional learning of English teachers.

It is clear from this research that it is very challenging to gain access to the planning expertise of an expert English teacher who has progressed along the Dreyfus continuum. Their expertise development necessitates increasingly relying on tacit components, for example what seem to be 'invisible' modes of planning and having no 'visible' plans that others can 'see'. It is clear that 'invisible' is not the same as 'inactive', internal reflective planning is highly active and constant but it can be 'inaccessible' to other developing English Teachers. The use of the think aloud process in research is one means of articulating expert performance. In practice once beginning teachers have been 'trained' in planning that tends to be the end of their conversations with other teachers about learning design, most developmental input comes from lesson observation with some comments on a written plan. What we suggest is that time needs to be devoted to conversations about planning a good learning design in English, using a 'think aloud' mode and where the participants are consciously from different stages of the Dreyfus model but equals in an effort towards each improving their English teaching. 


\section{References}

Alexander, P. (2003) The development of expertise: the journey from acclimation to proficiency. Educational researcher, 32(8), pp.10-14.

Badjanova, J. \& Iliško, D. (2015) Holistic approach as viewed by the basic school teachers in Latvia. Discourse \& Communication for Sustainable Education, 6, 132-140.

Benner, P. (2004) Using the Dreyfus model of skill acquisition to describe and interpret skill acquisition and clinical judgment in nursing practice and education. Bulletin of Science, Technology \& Society, 24, 188-199.

Berliner, D. C. (2004) Describing the behavior and documenting the accomplishments of expert teachers. Bulletin of Science, Technology \& Society, 24, 200-212.

Betsch, T. \& Glockner, A. (2010) Intuition in judgment and decision making: extensive thinking without effort. Psychological Inquiry, 21, 279-294.

Blomberg, S. \& Knight, B. A. (2015) Investigating novice teacher experiences of the teaching dynamics operating in selected school communities in Finland. Improving Schools, 18, 157170.

Centre for Evaluation and \& Monitoring (CEM) Durham University (2014). Classroom observation: its harder than you think. Centre for Evaluation and Monitoring, 2014-01.

Chua, B. L., Tan, O. S. \& Liu, W. C. (2016) Journey into the problem-solving process: Cognitive functions in a PBL environment. Innovations in Education and Teaching International, 53, 191-202.

Coe, R., Aloisi, C., Higgins, S., Major, L. E. \& Sutton, T. (2014) What makes great teaching? Review of the underpinning research, Sutton Trust. Available at: https://www.suttontrust.com/research-paper/great-teaching/ [Accessed 07 August 2017].

Colarusso, D. (2010). Teaching English in a multicultural society: three models of reform. Canadian journal of education, 33(2), pp.432-458.

Dall'Alba, G. and Sandberg, J., 2006. Unveiling professional development: a critical review of stage models. Review of educational research, 76 (3), pp.383-412.

Dreyfus, S. E. (2004) The five-stage model of adult skill acquisition. Bulletin of Science, Technology \& Society, 24, 177-181.

Eley, M. G. (2006) Teachers' conceptions of teaching, and the making of specific decisions in planning to teach. Higher Education: The International Journal of Higher Education and Educational Planning, 51, 191-214.

Enow, L. (2016) Teacher cognition: a study of secondary English teachers. University of Reading.

Enow, L \& Goodwyn, A. (2017) 'Multimethod study: secondary english teacher cognition' [online]. SAGE Research Methods Cases. [Accessed 27 June 2017] 10.4135/9781473993976. Ericsson, K. A. (2005) Recent advances in expertise research: a commentary on the contributions to the special issue. Applied Cognitive Psychology, 19, 233-241.

Ericsson, K. A. \& Pool, R. (2016) Peak : secrets from the new science of expertise. London: Penguin Random House.

Exley, B. and Chan, M. Y., (2014) Tensions between policy and practice: reconciliation agendas in the Australian curriculum English. English teaching: practice and critique,13(1), pp.55-75.

Farrell, T. S. C. (2014) 'I feel like I've plateaued professionally ... gone a little stale': midcareer reflections in a teacher discussion group, Reflective Practice, 15:4, 504-517.

Gholami, K. (2011) Moral care and caring pedagogy: two dimensions of teachers' praxis. Pedagogy, Culture \& Society, 19, 133-151. 
Gibbons, S. (2009) Lessons from the past?, English Teaching: Practice \& Critique (University Of Waikato), 8, 1, pp. 64-75, Education Research Complete, EBSCOhost, viewed 7 August 2017.

Gibbons, S. (2017) English and its Teachers: a history of policy, pedagogy and practice. London, Routledge.

Gibson, S. A. \& Ross, P. (2016) Teachers' professional noticing. Theory Into Practice, 55, 180-188.

Gitomer, D. H. \& Zisk, R. C. (2015) Knowing what teachers know. Review of Research in Education, 39, 1-53.

Goodwyn, A. (1997) Developing English teachers : the role of mentorship in a reflective profession, Buckingham [England]; Philadelphia, Open University Press.

Goodwyn, A. (2002) Improving literacy at KS2 and KS3. London: Sage.

Goodwyn, A. (2011) The expert teacher of English. Milton Park, Abingdon, Oxon, Routledge.

Goodwyn, A. (2017a.) Expert teachers: an international perspective, Abingdon, Routledge.

Goodwyn, A. (2017b) From personal growth (1966) to personal growth and social agency (2016) - Proposing an invigorated model for the 21st century. English in Australia (01552147), 52, 66.

Gorard, S. (2017) How prepared do newly-qualified teachers feel? Differences between routes and settings. Journal of Education for Teaching, 43, 3-19.

Hagger, H., Mutton, T. \& Burn, K. (2011) Surprising but not shocking: The reality of the first year of teaching. Cambridge Journal of Education, 41, 387-405.

Hall, T. J. \& Smith, M. A. (2006) Teacher planning, instruction and reflection: What we know about teacher cognitive processes. Quest (00336297), 58, 424-442.

Hallam, S. (2010) Transitions and the development of expertise. Psychology Teaching Review, 16, 3-32.

Hattie, J. (2012) Visible Learning for Teachers: Maximizing Impact on Learning, London: Routledge.

Hattie, J. (2003) Teachers make a difference: what is the research evidence? [Camberwell, Vic.], Australian Council for Educational Research. $<$ http://www.educationalleaders.govt.nz/Pedagogy-and-assessment/Building-effectivelearning-environments/Teachers-Make-a-Difference-What-is-the-Research-Evidence.> Hewitt, D. (2008) Understanding effective learning: strategies for the classroom, Maidenhead, McGraw-Hill Open University Press.

Hudson, P. (2013) Strategies for mentoring pedagogical knowledge, Teachers and Teaching, 19:4, 363-381.

Hollins, E. R. (2011) Teacher preparation for quality teaching. Journal of Teacher Education, 62, 395-407.

Hopmann, S. (2007) Restrained teaching: The common core of didaktik. European Educational Research Journal, 6, 109-124.

Ingvarson, L. (2010) Recognising accomplished teachers in Australia: Where have we been? Where are we heading? Australian Journal of Education, 54, 46-71.

Ingvarson, L. \& Rowe, K. (2008) Conceptualising and evaluating teacher quality: substantive and methodological issues. Australian Journal of Education (ACER Press), 52, 5-35.

Jóhannesson, I. Á. (2006) Concepts of teacher knowledge as social strategies. Pedagogy, Culture \& Society, 14, 19-34.

John, P. D. (2006) Lesson planning and the student teacher: re-thinking the dominant model. Journal of Curriculum Studies, 38, 483-498. 
Kinchin, I. M. and Cabot, L. B. (2010) Reconsidering the dimensions of expertise: from linear stages towards dual processing. London Review of Education, 8(2), 153-166.

Kumi-Yeboah, A. \& James, W. (2012) Transformational teaching experience of a novice teacher: A narrative of an award-winning teacher. Adult Learning, 23, 170-177.

Lajoie, S. P. (2003) Transitions and trajectories for studies of expertise. Educational Researcher, 32, 21-25.

Lampert, M., Franke, M. L., Kazemi, E., Ghousseini, H., Turrou, A. C., Beasley, H., Cunard, A. \& Crowe, K. (2013) Keeping it complex: Using rehearsals to support novice teacher learning of ambitious teaching. Journal of Teacher Education, 64, 226-243.

Loughran, J. (2010) What expert teachers do : enhancing professional knowledge for classroom practice, London; New York, Routledge.

Loughran, J. (2013) Pedagogy: Making sense of the complex relationship between teaching and learning. Curriculum Inquiry, 43, 118-141.

Lyon, L. J. (2015) Development of teaching expertise viewed through the Dreyfus model of skill acquisition, Journal of the Scholarship of Teaching and Learning, Vol. 15, No. 1, pp. 88 $-105$.

Maclellan, E. (2012) The psychological dimension of transformation in teacher learning. Teaching Education, 23, 411-428.

Matthewman, S., (2014) Clearing the ground for a greener New Zealand English. English teaching: practice and critique, 13(1), pp.95-111.

McCutcheon, G. \& Milner, H. R. (2002) A contemporary study of teacher planning in a high school english class. Teachers and Teaching, 8, 81-94.

McGill, M. (2007) Tapping into the tacit. International Journal of Learning, 13, 169-186.

Mena Marcos, J. J., Sánchez, E. \& Tillema, H. (2008) Teachers reflecting on their work: articulating what is said about what is done. Teachers and Teaching, 14, 95-114.

Moran, S. (2008) After behaviourism, navigationism? Irish Educational Studies, 27, 209-221.

Mutton, T., Hagger, H. \& Burn, K. (2011) Learning to plan, planning to learn: the developing expertise of beginning teachers. Teachers and Teaching, 17, 399-416.

O’Neill, S., Geoghegan, D. \& Petersen, S. (2013) Raising the pedagogical bar: Teachers' coconstruction of explicit teaching. Improving Schools, 16, 148-158.

Peercy, M.M., Martin-Beltrán, M., Silverman, R.D., and Daniel, S. (2015) Curricular design and implementation as a site of teacher expertise and learning. Teachers and Teaching ,21, No. 7, 867-893.

Plaut, S. (2006) "I Just Don't Get It": Teachers' and students' conceptions of confusion and implications for teaching and learning in the high school english classroom. Curriculum Inquiry, 36, 391.

Ryan, M., Fook, J. \& Hawkins, L. (1995) From beginner to graduate Social Worker: Preliminary findings of an Australian longitudinal study, British Journal of Social Work, 25, 17-35.

Ryan, T. G. (2011) The teacher/ researcher and the role of pre-understanding: A personal analysis. New Zealand Journal of Teachers' Work, 8, 220-228.

Shulman, L. (2013) Those who understand: Knowledge growth in teaching. Journal of Education- Boston university school of Education. 193, 1-12.

Sinnema, C., Meyer, F., \& Aitken, G. (2017) Capturing the complex, situated, and active nature of teaching through inquiry-oriented standards for teaching. Journal of Teacher Education. 68, 9-27.

Slater, H., Davies, N. M. \& Burgess, S. (2012) Do teachers matter? Measuring the variation in teacher effectiveness in england. Oxford Bulletin of Economics \& Statistics, 74, 629-645.

Sperling, D., and DiPardo, A., (2008) English education research and classroom practice: new directions for new times. Review of education research, 32, vol.1, pp.62-108. 
Strom, K. J. (2015) Teaching as assemblage: Negotiating learning and practice in the first year of teaching. Journal of Teacher Education, 66, 321-333.

Swinson, J., \& Harrop, A. (2012) Positive psychology for teachers. Milton Park, Abingdon, Oxon, Routledge.

Tirri,K. \& Ubani, M. (2013) Education of Finnish student teachers for purposeful teaching, Journal of Education for Teaching, 39:1, 21-29.

Tsui, A. B. M. (2009) Distinctive qualities of expert teachers. Teachers \& Teaching, 15, 421439.

Vesterinen, O., Toom, A. \& Patrikainen, S. (2010) The stimulated recall method and ICTs in research on the reasoning of teachers. International Journal of Research \& Method in Education, 33, 183-197.

Ward, L., Grudnoff, L., Brooker, B. \& Simpson, M. (2013) Teacher preparation to proficiency and beyond: Exploring the landscape. Asia Pacific Journal of Education, 33, 6880 .

Waring, M., \& Evans, C. (2015) Understanding pedagogy: developing a critical approach to teaching and learning. Abingdon, Routledge.

West, A., Mattei, P. \& Roberts, J. (2011) Accountability and sanctions in English Schools. British Journal of Educational Studies, 59, 41-62.

Woollard, J. (2010) Psychology for the Classroom: Behaviourism. Abingdon, Oxon: Taylor \& Francis. 